\title{
Law \& Economics as a Theory of Decision Making in Legal Contexts - Decision Theoretical Foundations, Their Misinterpretations and Excessive Claims of Economic Analysis of Law
}

\begin{abstract}
The article treats law \& economics as a proposal of a theory of decision making in legal settings. It is emphasized that the distinction between two approaches in economic analysis of law: the neoclassical and the behavioral one, is made with reference to two different theories of decision making applied in the realm of each approach. The neoclassical approach is based on the theory of expected utility, whereas the behavioral one - on prospect theory. According to the scholars on both sides, application of decision theory might be helpful in influencing behavior by legal norms in a more sophisticated way. The claim of the article is that law \& economics scholars misinterpret the assumptions and propositions of the theories and/or formulate excessive claims, if they argue that decision theoretical findings provide knowledge about the way in which people's decisions are influenced by law.
\end{abstract}

1. Introduction - law \& economics as a theory of decision making in legal contexts

Economic analysis of law (EAL, also called law \& economics - L\&E) is based on the idea that an analysis of content of legal rules should be employed with tools of economic theories. Many schools and approaches constitute the EAL field (schools such as Chicago School, New Heaven School, Virginia School, Austrian School, and approaches such as neoclassical, behavioral, institutional, social norms and law and even neuroeconomics and law). Rapid development of the movement started after the publication of R. Posner's The Economic Analysis of Law ${ }^{1}$ in the 70s of the $20^{\text {th }}$ century. However, a decade before R. Posner, the precursors of EAL: R. Coase ${ }^{2}$, G. Calbresi ${ }^{3}$ and A. Al-

R. Posner, Economic Analysis of Law, Boston 1972.

R. Coase, The problem of social cost, "Journal of Law and Economics" 1960/3, pp. 1-44.

G. Calabresi, Some thoughts on risk distribution and the law of torts, "Yale Law Journal” 1961/70, pp. 499-553 
chian ${ }^{4}$ published their works about economic analysis of private law. Nowadays L\&E has become a separate subject of studies at law schools in the USA and countries of Western Europe. Interest in that approach is also growing in the rest of the world (i.a. Central and Eastern Europe, Asia). Moreover, L\&E methods are used in business, as well as in public policy contexts - in recommendations and analyses of legislative proposals.

Since the 90s a split within the EAL movement has been observed - between those who support the application of neoclassical economics to law (neoclassical approach) and the proponents of extending analyses by incorporating methods of other sciences - psychological, sociological or neuroscientific ones (behavioral approach, social norms and law approach, neuroeconomics and law approach).

Law \& economics might be viewed as one of legal theoretical approaches to analysis and examination of law - if law is treated as a subject of intellectual and scientific inquiry. It is emphasized by legal theorists that EAL is rooted in the tradition of American legal realism. Legal realism questioned the possibility of establishing an autonomous ${ }^{5}$, separate method of analyzing law and postulated an integration of methodologies stemming from social sciences in order to explain different aspects of law and legal practices. Indeed, the proponents of L\&E stress the importance and significance of economics as a social science, which provides a method for an analysis of law. What is more, they claim that economics offers the most sophisticated theories and methodologies of all social sciences and for that reason the application of economics to law and legal issues results in precise and verifiable hypotheses about the functioning of law.

The application of economic theories to the analysis of law is justified on the basis of several arguments. First of all, it is claimed that economics provides an appropriate (precise, verifiable ${ }^{6}$ ) method for the analysis, which has been mentioned in the previous paragraph (theoretical and methodological justification). Another argumentation emphasizes the fact that law regulates i.a. the spheres and aspects of social reality described and explained by economic theories (as in the case of e.g. entrepreneur, business, competition law). Therefore, it is argued that a law maker should take into account the knowledge about economic relations and principles while regulating these social spheres (justification based on a common subject of economic inquiry and legal regulation). Some scholars argue that law has deep economic roots, since many legal rules (especially the ones which emerged at the early stage of societal development) have economic rationale and they might have developed in order to protect economic interests (genetic justification). Another way of reasoning refers to instrumental and behavioral dimensions of law. If law is regarded as an instrument of influencing behavior, economics provides a law maker with the knowledge about how to affect behavior in the most effective way (instrumental and behavioral justification). Finally, instrumental justification is related to the one formulated from policy perspective (political justification). It is inspired by the idea that the analysis of law which is based on eco-

\footnotetext{
A. Alchian, Some economics of property rights, "Il Politico"1965/30, pp. 816-829.

What also R. Posner does in his article - see R. Posner, The decline of law as an autonomous discipline: 1962-1987, "Harvard Law Review"1987/761, pp. 761-780.

6 I use the term "verifiable" in accordance with rhetoric often used in economic works. In methodology of economics there is a discussion about falsificationism in economics. Although I am aware of this dispute, I do not think it is fully justified to use the term "falsifiable" instead of "verifiable", since it would not represent the standpoint of all economic theorists. More about the discussion: M. Blaug, Methodology of economics or how economists explain, Cambridge 1992, chapters 3-5.
} 
nomic theories is supposed to inform a policy/law maker about a possible change in behavior resulting from change in law. The advantage gained from applying economics in the processes of law and policy making is supposed to be the predictability of results and outcomes of legal change.

My claim throughout this paper is that law \& economics may be treated as a theoretical project of proposing a theory of decision making in legal settings. If law is treated as an instrument of influencing behavior, a law maker has to be informed about changes in behavior which result from changes in law. The best, if not the only one, way to inform a law maker about these changes is to provide him/her with a theory of behavior (decision making). Economic analyses of law are carried out on the basis of theories of decision making used in economics. Expected utility theory is a theory used in the neoclassical approach to law \& economics, whereas prospect theory - in the behavioral approach. $^{7}$

Support for my interpretation of law \& economics as a theory of decision making in legal settings may be found in numerous explicit references to decision theories expressed in works of law \& economics scholars, as well as in careful examination of some economic analyses of law they propose. I will refer to the latter point later - in subsections devoted to economic analyses of tort law and litigation law.

However, before I move to general remarks about theories of decision making, I suggest having a look at what the leading law \& economics scholars say about the presence of decision theory in EAL. For example, R. Cooter and T. Ulen write in the introduction to their textbook: "Generalizing, we can say that economics provides a behavioral theory to predict how people respond to changes in laws. This theory surpasses intuition, just as science surpasses common sense." ${ }^{\text {S }}$. Shavell, an adherent of the neoclassical approach to law, mentions: "Given the characterization of individuals' behavior as rational, the influence of legal rules on behavior can be ascertained. This can be done with definitude in the world of the models, because all relevant assumptions about individuals' desires, their knowledge, their capabilities, and the environment will have been made explicit. For example, whether a person will drive carefully will be determinable, for it will have been stated how difficult it is for the person to exercise precaution, whether the person will himself be at risk of injury from an automobile accident, what the rule of liability is, what circumstances will give rise to suit, whether the person owns accident insurance and liability insurance, and so forth." ${ }^{\prime} \mathrm{C}$. Sunstein, a proponent of behavioral law $\&$ economics starts the introduction to the handbook edited by him in the following way: "How does law actually affect people? What do people do in response to the law? Why is the law as it is? How can law be enlisted to improve people's lives? This book attempts to provide some answers (...). The purpose of this book is to bring new and more accurate understanding of behavior and choice to bear on law."10

Finally, J. Arlen and E. Talley in a handbook on experimental law \& economics summarize the research in economic analysis of law as follows: "A central function of law is to influence and shape human behavior. Liability rules, negligence standards, punitive damages, evidentiary presumptions, criminal penalties, default rules of contracting, and rules of jurisdictional reach: each plays an important role within

\footnotetext{
I provide characteristics of both approaches further in the text.

R. Cooter, T. Ulen, Law \& economics, Addison Wesley 2004, p. 4.

S. Shavell, Economic analysis of accident law, "Working Paper 9694 National Bureau of Economic Research" 2003, p. 1.

10 C. Sunstein, Introduction, in: Behavioral law \& economics, edited by C. Sunstein, Cambridge 2000, p. 1.
} 
a larger normative enterprise of law, discouraging socially undesirable activities while encouraging socially desirable ones. Any legal scholar, policy-maker or judge who seeks to use law for instrumental purposes must inevitably contend with understanding and forecasting how law and human behavior interact. Such forecasts are not easy. Among other things, they minimally require a coherent theory of how people behave in legal environments. Moreover, such a theory must be capable of predicting how legal structures shape incentives, coordinate beliefs and communicate expectations, and also how such factors are likely to interact to affect actors' decisions."11

On the whole, the adherents of both approaches are of the opinion that reference to and reliance on the theories of decision making might inform EAL scholars about the ways in which law influences behavior.

\section{Two theories of decision making which have inspired law $\&$ economics scholarship}

In decision theory, the distinction between normative and descriptive theories of decision making is widely accepted. Normative theories are supposed to define or refer to a certain norm of rationality and "seek to yield prescriptions about what decision makers are rationally required - or ought - to do." 12 The norm of rationality defined and understood in such a way allows to assess people's compliance with it (compliance is called rational behavior, whereas noncompliance is not rational in the light of normative theory). On the other hand, in descriptive theories of decision making no rational standard of behavior is assumed. Their aim is to focus on the actual processes of decision making. In most cases, descriptive theories rely on experimental methods. Expected utility theory is classified as normative theory of decision making, whereas prospect theory as the descriptive one.

Below I present quite a detailed reconstruction of the assumptions and reasoning underlying both theories. My aim is to refrain from following the line of interpretations of the theories present in the literature and stay very close to the text, as well as to initial motivations of the founders of modern decision theories.

\subsection{Expected utility theory}

The abovementioned distinction between normative and descriptive theories of decision making does not seem to be so obvious if one takes a closer look at works which provide axiomatization for the principle of maximizing expected utility. ${ }^{13} \mathrm{~J}$. von Neumann and O. Morgenstern in the second edition of their work on game theory ${ }^{14}$ propose mathematical justification for maximization principle. They notice the importance of optimization in economic theory, where consumers' aims are described as maximization of utility (satisfaction from consumption), producers' - as maximization of profit, and they ask whether optimization principle could be mathematically justified. Before they move on to their main task (formulation of axioms), they make

11 J. Arlen, E. Talley, Experimental law and economics, Edward Elgar Publishing 2008, p. xv.

12 M. Peterson, An introduction to decision theory, Cambridge 2009, p. 3.

13 Principle of maximizing expected utility theory in formal notation: EU $\left(\mathrm{x}_{1}, \mathrm{p}_{1} ; \ldots ; \mathrm{x}_{\mathrm{n}} \mathrm{p}_{\mathrm{n}}\right)=\mathrm{p}_{1} \times \mathrm{u}_{1}\left(\mathrm{x}_{1}\right)+\mathrm{p}_{2} \times \mathrm{u}_{2}\left(\mathrm{x}_{2}\right)+$ $+\ldots+p_{n} \times u_{n}\left(x_{n}\right)$, where $x$ represents an event, $p$-probability of an event occurrence, $u-u$ tility of an event.

14 J. von Neumann, O. Morgenstern, Theory of games and economic behavior, Princeton 1947. 
remarks about their view on rationality (of economic agents). "The individual who attempts to obtain (...) respective maxima is also said to act 'rationally'. But it may safely be stated that there exists, at present, no satisfactory treatment of the question of rational behavior (...). This is an exceedingly difficult task, and we can safely say that it has not been accomplished in the extensive literature about the topic. The chief reason for this lies, no doubt, in the failure to develop and apply suitable mathematical methods to the problem; this would have revealed that the maximum problem which is supposed to correspond to the notion of rationality is not at all formulated in an unambiguous way. Indeed, a more exhaustive analysis [their axiomatic approach - my remark] reveals that the significant relationships are much more complicated than the popular and the "philosophical" use of the word 'rational' indicates." 15

It follows from the citation that the authors do not treat optimization as an obvious norm of rationality. What they aim is to provide a mathematical analysis of the notion of rationality. Or, in other words, as I have already mentioned, they attempt to provide mathematical (axiomatic) justification for the principle of maximization (of expected utility). J. von Neumann and O. Morgenstern try to indicate formal conditions under which the principle holds. However, they refrain from normative claims that individuals should follow the principle of optimization (maximization) so as to behave rationally.

In order to formulate axioms, they make several assumptions about notions such as utility, preferences, events, probability, as well as about the conditions under which decisions are taken (e.g. access to information, agents' ability to compute and assess probabilities).

First of all, they assume that utility is a numerical entity. Since they want to avoid problems with defining what utility really is or how to measure it, they only claim that utility can be ranked. Therefore, in order to be able to establish ranking of utilities, J. von Neumann and O. Morgenstern further assume that "imagined events can be combined with probabilities. And therefore the same must be assumed for the utilities attached to them - whatever they may be." ${ }^{\prime 16}$ Moreover, they state that measurement of utility order (based on the distances between utilities) should be based on immediate sensation. Sensation in that case is the "immediate sensation of preference". ${ }^{17}$ It means that by observing agents' choices it is possible to state which event/object is preferable more or less than another. While facing a choice problem: which of those two to choose, agents decide to take an object/event which they prefer more. Preference is not defined, but it can be observed during decision making as a result of choice behavior. It is important to stress that such "revealed" preferences merely enable to say that one utility is greater than another.

They treat events as "future event", which occur at one standardized moment in the immediate future. This assumption allows the authors to "make all logically possible alternatives equally admissible ${ }^{18 "}$, as well as to avoid problems of preferences between events occurring in different time periods and influences of decision outcomes by discounting over time. ${ }^{19}$

\footnotetext{
J. von Neumann, O. Morgenstern, Theory of games..., p. 9.

J. von Neumann, O. Morgenstern, Theory of games..., p. 20.

J. von Neumann, O. Morgenstern, Theory of games..., p. 16.

J. von Neumann, O. Morgenstern, Theory of games..., p. 19.

19 Since the beginning of classical economics, economists have been focusing on the problem of intertemporal choices - e.g. between goods obtained in different periods of time. Time discounting means that a subject cares less about future goods or events than about the present ones. In neoclassical economics it means that expected utility of a future
} 
Furthermore, they accept frequency interpretation of probability because they are interested in formalization based on a numerical concept of utility. Consequently, in order to construct numerical estimation of utility, they refer to a numerical concept of probability. ${ }^{20}$

J. von Neumann and O. Morgenstern assume that all economic agents are fully informed about characteristics of the situation in which they take decisions, as well as they are able to perform all mathematical and statistical operations needed to assess the probability of events.

The authors use interval scales in order to measure distances between utilities. Interval scales reflect distances (but not ratios) between the quantities being measured. In mathematical terms this kind of scales is invariant up to positive linear transformations - any interval scale can be transformed into another by multiplying each entry by a positive number and adding a constant. In case of utilities which are quantities correlated with numbers linear transformations allow for correlating numbers with utilities in many ways, provided that they satisfy the conditions of positive linear transformations. ${ }^{21}$

Axiomatization is based on the concept of lottery, which is defined as an event with known probabilities. Lottery is defined inductively, which means that also a combination of lotteries with stated probabilities ${ }^{22}$ falls within axioms.

The idea that strength of someone's preference (and accordingly distances in utility) can be ranked refers to the possibility of stating a risk which someone is willing to take in order to receive/have something (event). Risk is reflected by the probability of event occurrence. The idea might be illustrated on the basis of the following reasoning. Let's imagine having three events that can be ranked in the following order: $\mathrm{x}, \mathrm{y}, \mathrm{z}$. Event $\mathrm{x}$ is more preferable than event $y$, and $y$ is more preferable than $z$. If one wants to know how much more event $\mathrm{x}$ is preferable to $\mathrm{z}$, one can construct the following choice problem: choose between $y$ and lottery $\mathrm{L}(\mathrm{b} ; \mathrm{x}, \mathrm{z})^{23}$ and estimate probability $\mathrm{b}$ under which you will be indifferent between two choices. Ranking between these three events can be represented in the following way:

$\mathrm{x}$

$\mathrm{y}, \mathrm{L}(\mathrm{b} ; \mathrm{x}, \mathrm{z})$

$\mathrm{Z}$

It is important to notice that if lotteries are ranked in this manner, their utilities equal their expected utilities. ${ }^{24}$

event is diminished by future consequences (uncertainty, changing tastes). This intuition was formalized by P. Samuelson, see P. Samuelson, A note on measurement of utility, "The Review of Economic Studies" 1937/4/2, in his discounted utility model, which enables to calculate present utility of a good (event) received at a certain future moment.

20 In frequency interpretation, probability is expressed as a ratio between the numbers of event occurrences and the total number of observed cases.

21 Example of positive linear transformations are Centigrade and Fahrenheit scales. They both reflect differences in temperature. Any number of temperature on one scale can be transformed into a number on the other scale - on the basis of function $\mathrm{F}=1,8 \mathrm{C}+32$ or $\mathrm{C}=(\mathrm{F}-32) ; 1,8 . \mathrm{F}$ and $\mathrm{C}$ refer accordingly to degree measurement on Fahrenheit and Centigrade scale.

22 Inductive definition of lottery:

1. Every basic prize $(\mathrm{x}, \mathrm{y}, \mathrm{z} \ldots ., \mathrm{n})$ is a lottery.

2. If $\mathrm{L} 1$ and $\mathrm{L} 2$ are lotteries, so is $\mathrm{L}(\mathrm{a}, \mathrm{L} 1, \mathrm{~L} 2)$ where $0<\mathrm{a}<1$.

3. Something is a lottery if and only if it can be constructed according to conditions 1 and 2.

23 Notation $\mathrm{L}(\mathrm{a} ; \mathrm{x}, \mathrm{z})$ means that probability of $\mathrm{x}$ occurrence is a and occurrence of $\mathrm{z}$ is $1-\mathrm{a}$.

${ }^{24}$ Utility of event y equals utility of lottery (expected utility), whereas utility of lottery is a. It follows that utility of $y$ is a and utility of lottery (expected utility) is also a. 
J. von Neumann and O. Morgenstern proposed the following axiomatization of the preference relation:

Axiom $1 \mathrm{x}>\mathrm{y}$ or $\mathrm{y}<\mathrm{x}$ or $\mathrm{x}=\mathrm{y}$ (completeness);

Axiom 2 If $x>y$ and $y>z$, then $x>z$ (transitivity);

Axiom $3 \mathrm{x}>\mathrm{y}$ if and only if $\mathrm{L}(\alpha, \mathrm{x}, \mathrm{z})>\mathrm{L}(\alpha, \mathrm{y}, \mathrm{z})$ (independence);

Axiom 4 If $\mathrm{x}>\mathrm{y}>\mathrm{z}$ then $\mathrm{x}>\mathrm{L}(\alpha, \mathrm{x}, \mathrm{z})>\mathrm{z}$ (continuity);

for lotteries $\mathrm{x}, \mathrm{y}, \mathrm{z}$.

Completeness means that it is possible to state any preferences between some pairs of events. It excludes the incomparability of any two lotteries from a considered set. Independence axiom states that preference between two events ( $\mathrm{x}$ and $\mathrm{y}$ ) does not change by combining those two events into lotteries with any other third event $(\mathrm{z})$. Continuity allows to rank all lotteries from a given set into hierarchical order which reflects distances $(\alpha)$ between them.

Von Neumann and Morgenstern theorem states that is possible to assign a numerical order to a rank of lotteries which reflects distances between utilities attached to lotteries.

vNM theorem: Relation > satisfies vNM1-4 if and only if there exists a function $\mathrm{u}$ that takes a lottery as its argument and returns a real number between 0 and 1 , such as:

1) $x>y$ if and only if $u(x)>u(y)$

2) $\mathrm{u}(\alpha, \mathrm{x}, \mathrm{y})=\alpha \mathrm{u}(\mathrm{x})+(1-\alpha) \mathrm{u}(\mathrm{y})$

3) For every other function u' satisfying 1 and 2 there are numbers $c>0$ and $d$ such that

$\mathrm{u}^{\prime}=\mathrm{cu}+\mathrm{d}$

The sense of the theorem is that utility function assigns numerical values (from 0 to 1 ) to lotteries in such a way that higher numbers correspond to higher utilities (condition 1 of the theorem) and utilities of compound lotteries equal expected utilities of their components (condition 2). Condition 1 and 2 are called representation part of the theorem, which shows that nonnumerical structures can be represented numerically. Condition 3 is a uniqueness part of the theorem. It states that functions which satisfy representation conditions can be transformed into each other as a result of positive linear transformation.

The theorem has been proved by assigning numbers to each lottery and then verifying that the resulting numerical scale has the properties postulated by axioms.

The axiomatization proposed by J. von Neumann and O. Morgenstern in order to mathematically justify the principle of maximization has been called "expected utility theory". It is important to note that they did not introduce the term; they neither claimed that any agent should/is supposed to "follow the axioms". These stronger (normative) claims have been formulated by the readers and interpreters of J. von Neumann and O. Morgenstern's work, i.a. by proponents of the neoclassical approach in law \& economics.

\subsection{Prospect theory}

The founders of prospect theory, A. Tversky and D. Kahneman, in their seminal article $^{25}$ treat expected utility theory as a descriptive theory of decision making. The aim of their analysis and investigation is to examine predictive power of this theory. They

25 D. Kahneman, A. Tversky, Prospect theory: an analysis of decision under risk, “Econometrica” 1979/47/2, pp. $263-291$. 
construct several choice problems and presented them to people in experimental situations in which "preferences systematically violate the axioms of expected utility theory." 26 The analyses of decisions taken by people while dealing with these problems led to formulation of several effects (certainty, reflection and isolation effect) related to violation of the predictions based on expected utility theory. These observations were also basis and inspiration for the proposal of an alternative theory of decision under risk - prospect theory.

A. Tversky and D. Kahneman claim that application of expected utility theory is based on tenets such as: expectation ${ }^{27}$, asset integration ${ }^{28}$, risk aversion. ${ }^{29}$ Instead of using the concept of lottery, they introduce the concept of prospect (symbolically $(x, p)$ ), which is event $\mathrm{x}$ with probability $\mathrm{p}$. They point out that according to expected utility theory, utilities of outcomes (events) are weighted by probabilities - a principle which they are going to refute.

They demonstrate certainty effect using an example of several choice problems, inspired by the so called Allais paradox. ${ }^{30}$ In these problems, people overweight outcomes (events) which are considered certain. One can also observe reduction in desirability of a prospect if it changes from sure gain to merely probable. In the experiments designed by A. Tversky and D. Kahneman the subjects faced two problems. In the first problem, they had to choose between option A (with probable payoff) or B (with certain payoff). ${ }^{31}$ In the second problem, they decided between options $\mathrm{C}$ and $\mathrm{D}$ (both merely probable). ${ }^{32}$ It occurred that most of the respondents chose $\mathrm{B}$ in the first problem and $\mathrm{C}$ in the second one. However, alternatives $\mathrm{C}$ and $\mathrm{D}$ were obtained from $\mathrm{A}$ and $\mathrm{B}$ respectively by subtracting probability 0.66 of winning 2400 . Subtraction has been done in accordance with independence axiom (substitution axiom).$^{33}$ This preference reversal demonstrates that certainty itself is valued more than expected utility of a prospect which has a higher monetary value than certain payoff. ${ }^{34}$ According to A. Tversky and D. Kahneman, the reduction in desirability and reversal of preferences violates the independence axiom of J. von Neumann and O. Morgenstern axiomatization.

26 D. Kahneman, A. Tversky, Prospect theory..., p. 263.

See footnote 13 .

28 Utility resulting from integration of prospect with asset exceeds the utility of the asset itself.

29 Agents prefer certain prospect $x$ to any risky prospect with expected value of $x$. This characteristic is a result of concavity of utility function in expected utility theory.

30 Allais paradox is a name of choice problem described for the first time by a French economist M. Allais, see M. Allais, $L e$ Comportement de l'Homme Rationnel devant le Risque: Critique des Postulats et Axiomes de l'Ecole Americaine, "Econometrica" $1953 / 21 / 4$, pp. 503-546. Example in the footnote below is almost identical with the alternatives presented by M. Allais - with the only difference that in his article monetary amounts associated with outcomes were much higher.

31 Problem 1 Choose between

A:

B:

2500 with probability $0,33 \quad 2400$ with certainty

2400 with 0,66

0 with 0,01

32 Problem 2 Choose between

$\mathrm{C}:$

2500 with $0,33 \quad 2400$ with 0,34

0 with $0,67 \quad 0$ with 0,66

33 In the article D. Kahneman, A. Tversky, Prospect theory..., pp. 263-291 they call violated axiom a substitution axiom claiming that the axiom states that "if $B$ is preferred to $A$, then any probability mixture $(B, p)$ must be preferred to mixture (A, p)". Substitution axiom might be viewed as a simplified version of independence axiom. Independence axiom states that if event $\mathrm{B}$ is preferred to event $\mathrm{A}$, then any lottery in which B occurs with probability $\mathrm{p}$ and any other event $\mathrm{C}$ - with probability of 1-p, must be also preferred to any lottery in which A occurs with probability $\mathrm{p}$ and any other event $\mathrm{C}$ - with probability 1-p. If the axiom states that preferences do not change in case of compound lotteries, it must also hold that all the more they do not change if probability of both events alters by the same fraction.

34 Expected utility of alternative A is 2409 
If follows from the reflection effect that reflection of prospects around a certain reference point (mostly zero in the system of coordinates) reverses the order of preferences. When people choose between certain positive prospects which they perceive as gains and risky prospects, they are risk averse (phenomenon of risk aversion in positive domain). On the other hand, if someone chooses between certain negative prospect perceived as a loss and a risky negative prospect, then he/she is more eager to take the latter (merely probable) outcome (risk seeking in negative domain). ${ }^{35}$ This means that the same psychological principle, overweighting of certainty, favors risk aversion in the domain of gains and risk seeking in the domain of losses. Thus certainty is desirable not in every choice alternative, contrary to the risk aversion tenet, ascribed by A. Tversky and D. Kahneman to expected utility theory.

Isolation effect is demonstrated on the basis of observation that in some choice situations people pass over the components shared by alternatives and focus only on these components that distinguish them. ${ }^{36}$

A. Tversky and D. Kahneman proposed an alternative theory of decision making under risk. The theory is supposed to generalize the abovementioned observations: that in decision processes, values are assigned rather to gains or losses than to final outcomes. In other words, carriers of value are changes in wealth, not in final outcomes/assets. What is more, in prospect theory, the probabilities are replaced by decision weights.

A. Tversky and D. Kahneman also claim that decision process consists of two phases: phase of editing prospects and phase of prospects' evaluation. Phase of editing is the first one and has a character of preliminary analysis of a prospect. It very often leads to simplification of the representation of a problem. Major editing operations of this phase are: coding, combination, segregation, cancellation, simplification or detection of dominance. ${ }^{37}$ For example, segregation leads to representation of a problem in such a way that the risky component of a prospect is separated from the riskless one; cancellation consists in discarding shared components and focusing only on those which distinguish prospects.

The authors propose formalization of evaluation phase. They claim that the "overall value of an edited prospect, denoted $V$, is expressed in terms of two scales $\varpi$ and $v . " 38 \pi(p)$ is a weighting function which reflects the impact which probability has on the overall value of a prospect, whereas $\mathrm{v}(\mathrm{x})$ is a value function which assigns to outcomes $(\mathrm{x})$ a subjective value of it.

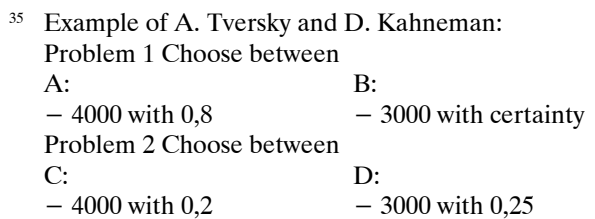

Respondents prefer $\mathrm{A}$ in the first problem and $\mathrm{D}$ in the second situation. Alternatives $\mathrm{C}$ and $\mathrm{D}$ are obtained by division of probabilities in A and B by 4. Therefore, according to independence axiom, respondents should be consistent and choose $\mathrm{C}$ in the second problem. However, in the first situation they choose $\mathrm{A}$ in order to avoid certain loss (risk seeking), whereas in the second situation they choose an alternative with a higher outcome.

36 A. Tversky and D. Kahneman observe isolation effect in the situation when people face two-stage game and are informed that the probability of moving to the next stage is 0,25 . Then at the second stage they have a choice between A: 4000 with 0,2 and B: 3000 with certainty. They should choose A or B before the game starts. Respondents mostly choose B. A. Tversky and D. Kahneman explain that the reason for this isrepresentation/formulation of choice problem in a sequential way instead of standard formulation (by estimating integral probability 0,2 of achieving outcome 4000 and 0,25 probability of winning 3000 ). In a sequential formulation people ignore the first stage of the game and consider choice between $\mathrm{A}$ and $\mathrm{B}$ as a problem.

37 D. Kahneman, A. Tversky, Prospect theory..., pp. 274-275.

38 D. Kahneman, A. Tversky, Prospect theory..., p. 275. 
Decision weights are revealed from the choices between prospects. It is important to note that they are not probabilities, but probabilities' weights. $\varpi(p)$ is usually smaller than $\mathrm{p}$, which means that the impact of perceived likelihood of an event on desirability of an outcome is usually smaller than the magnitude of $\mathrm{p}$.

Value function $(\mathrm{v}(\mathrm{x}))$ measures the value of departures from a reference point. On the basis of choice observation, A. Tversky and D. Kahneman formulated a hypothesis that value function is concave for changes in wealth above a reference point, and convex - below a reference point.

Basic equation for the overall value of a prospect is as follows:

$$
\mathrm{V}(\mathrm{x}, \mathrm{p} ; \mathrm{y}, \mathrm{q})=\varpi(\mathrm{p}) * \mathrm{v}(\mathrm{x})+\varpi(\mathrm{q}) * \mathrm{v}(\mathrm{y})
$$

whereas equation for strictly positive (all outcomes of a prospect are positive) or strictly negative prospects (all outcomes are negative):

$$
\mathrm{V}(\mathrm{x}, \mathrm{p} ; \mathrm{y}, \mathrm{q})=\mathrm{v}(\mathrm{y})+\varpi(\mathrm{p})[\mathrm{v}(\mathrm{x})-\mathrm{v}(\mathrm{y})]
$$

The basic equation shows that the overall value of a prospect is determined in such a way that probabilities attached to each event are weighed by function $\varpi$, and subjective values of each are determined by function $v$, which enables to measure the distance of event/outcome from a reference point (subjective value of it).

The second equation formalizes the overall value of a prospect with riskless and risky components. $\mathrm{v}(\mathrm{y})$ is a subjective value of a riskless component, whereas $\mathrm{v}(\mathrm{x})-\mathrm{v}(\mathrm{y})$ represents a subjective value of a risky component. Decision weight is applied to the risky component (value difference).

A. Tversky and D. Kahneman also "propose that very low probabilities are generally overweighed, that is $\varpi(\mathrm{p})>\mathrm{p}$ for small p." ${ }^{39}$ While dealing with alternatives between outcomes of the same expected utility, people have a tendency to choose the prospect with a high possible gain, even if it is very little probable, than a sure low gain. In a negative domain, they prefer a sure small loss to a large and little probable gain.

3. Two approaches in economic analysis of law - two theories of decision making applied

\subsection{Neoclassical law \& economics and expected utility theory}

\subsubsection{Assumptions}

It is rather a challenging task to reconstruct briefly the assumptions underlying application of neoclassical economics to law. However, it is certainly feasible to indicate economic concepts which have wide application in law: maximization, equilibrium and efficiency.

From the perspective of decision theory, the concept of maximization is a crucial one. Economic agents are supposed to maximize - e.g. satisfaction from consumption (consumers), profits (producers), revenues (bureaucracies). As I mentioned in subsec-

39 D. Kahneman, A. Tversky, Prospect theory..., p. 281. 
tion 2.1., maximization principle can be justified mathematically by referring to the concept of utility function, which assigns higher numbers to better alternatives. Neoclassical law \& economics scholars claim that maximizing behavior characterizes also agents acting in legal contexts. ${ }^{40}$ Furthermore, they define law as a price incentive which influences people's decisions by affecting their estimations of potential costs and benefits resulting from following legal norms/rules ${ }^{41}$ Thanks to approaching law in such a way it was and it is still possible to conduct economic analyses also in the areas of law such as criminal law, family law or environmental law. For example, if imposition of legal sanction in criminal law is understood as an introduction of price incentive, then it is possible to analyze the potential consequences of such a legal norm on the basis of economic theory. In the light of consumption theory, people respond to higher prices by reduction of consumption level. Analogically, one can predict that higher sanctions (like higher prices) will result in reduction of sanctioned behavior.

The concept of maximization is related to the concept of equilibrium. Equilibrium is a pattern of social interactions which persists as long as it is not disturbed/influenced by factors external to interacting behaviors. Interactions of maximizing actors are supposed to result in equilibrium.

S. Shavel ${ }^{142}$ underlies that an economic analysis of law addresses mainly two questions - the descriptive and the normative one. A descriptive analysis concerns the effects which law has on behavior, whereas a; normative one is conducted in order to evaluate legal norms from the perspective of social desirability. Evaluations are undertaken with reference to social welfare resulting from introduction of a legal norm. "One legal rule will be said to be superior to a second if the first rule results in higher level of the stated measure of social welfare." ${ }^{43}$ Law \& economics scholars refer to the notion of social welfare from welfare economics and to concepts of efficiency ${ }^{44}$ related to it.

\subsubsection{Example of analysis based on expected utility theory - tort law}

According to the definition present in American law, tort is a civil wrong, other than breach of contract, for which court provides remedy in a form of action for damages. Tort law deals with problems of establishing remedies for wrongdoing and of holding liable a person who causes harm. By assessing liability court proves whether such a person was negligent. Negligence is a behavior that falls short of a legal standard - the appropriate level of care called due care, designed in order to instruct about the extent of precautions.

40 I understand legal contexts as situations in which: legal norms are supposed to have an influence on behavior of their addressees; law makers are supposed to decide about content of legal norms; situations whose frames have been determined or specified by legal norms, like e.g. behaviors during dispute resolutions in court.

41 Following linguistic practice present in law \& economics literature, I use terms such as "legal norm", "legal rule", "legal regulation" as synonyms. I am aware of conceptual distinctions between them made by legal theory. However, law \& economics scholars use them in an ambiguous way, and attempts to attach precise meanings to these expressions would be redundant with respect to the task of presenting the main idea of the thesis. I treat all of them as legal norms - statements enacted by entitled entity, which prescribe behavior X to subject $\mathrm{Y}$ in circumstances $\mathrm{Z}$.

42 S. Shavell, Economic analysis...

43 S. Shavell, Economic analysis..., p. 2.

44 Pareto efficiency is a term used to characterize such an allocation of goods under which no one can be made better-off without making someone else worse-off. The allocation is supposed to be achieved as a result of interaction of utilitymaximizing consumers or profit-maximizing firms. Kaldor-Hicks efficiency characterizes the allocation of goods under which those who have been made better-off at the cost of others are able to compensate those who lose and still be better-off. 
In traditional legal scholarship, the norms of tort law have been understood as rules protecting and compensating a weaker side of legal relationships (e.g. a consumer against a producer who might cause harm by his/her production activity). In L\&E, tort law is treated rather as a tool of prevention. It is underlined that activity of both sides of legal relationship (a potential injurer and a potential victim) contributes to the occurrence of a harmful event (accident).

Therefore, in bilateral cases, two kinds of costs related to activity of both sides are taken into consideration in the analysis - the cost of care undertaken by an injurer and the cost of care undertaken by a victim. Furthermore, L\&E scholars also estimate the expected accident loss which is understood as the cost of accident multiplied by the probability of its occurrence. The total accident cost equals then the sum of the injurer's cost of care plus the victim's cost of care plus an expected accident loss. The achievement of the social goal (social welfare optimum) in this case means minimization of the total accident cost. With respect to the social goal, different liability rules are analyzed as more or less desirable from the social point of view.

The most important liability regimes analyzed and compared in L\&E are regime with no liability, strict liability rule (with its variance: strict liability rule with defense of contributory negligence) and negligence rule (with its variance: negligence rule with defense of contributory negligence).

Under no liability rule the injurer is not held liable, so he/she does not take care at all. Therefore, all costs of accident are borne by the victim, who has incentives to take care in order to lower his/her expected accident cost.

Under strict liability rule the injurer is liable for accident losses, no matter whether he/she takes due care in his/her actions. In that case the victim will be fully compensated by the injurer and won't have incentives to take care.

Under negligence rule both sides are obliged to take due care. If the victim does not do it, then he/she has to bear his/her costs, provided that th injurer takes due care. However, if the injurer does not exhibit due care, provided that the victim does, the injurer has to pay compensation equal of total accident cost. In a situation when both sides exhibit due care, the injurer bears merely the costs of expected accident loss.

What follows from the comparison of all those modeled versions of liability rules is that strict liability does not lead to socially optimal outcomes because it does not provide the victim with incentives to take care. Negligence rule, however, results in a socially optimal outcome because "parties have one of two sufficient reasons to take optimal care: either taking optimal care allows them to avoid entirely the bearing of accident losses (...) or else taking care reduces the level of (rather than the entirety of) expected losses that parties in fact bear." 45

Analyses of optimal (from the perspective of the society) liability regimes are extended in economic analysis of tort law by i.a. the influence of activity levels on both increase in expected accident losses and utility of injurers and/or victims, as well as by economic importance and incentivizing by the appropriate amount of damages adjudged, by the importance of insurance for optimality of liability rules. ${ }^{46}$

45 S. Shavell, Economic analysis..., p. 9.

46 See more in S. Shavell, Economic analysi..., chapters 2-6, as well as in S. Shavell, Liability for accidents in: Handbook of law \& economics, edited by M. Polinsky, S. Shavell, Elseivier 2007, vol.1 chapter 2, and R. Cooter, T. Ulen, Law..., chapter 9. 
It is noticeable that economic analyses of tort law might be presented in a form of decision theoretic structure. By this I mean that it is possible to conceptualize these analyses with the use of the components of every decision problem's formalization in the theories of decision making: acts, states and outcomes. In this case we can indicate two acts: "take due care" or "not to take due care". States (of the world) depend on what the other side of the bilateral relation does (whether he/she takes care or not, whether his/her level of activity is high or low, whether he/she purchases insurance or not). Outcomes are understood as expected costs of an accident which each agent has to expect to bear - the costs of an accident are calculated in the way mentioned above, multiplied by the probability of accident occurrence. According to the principle of expected utility maximization, each agent should choose the act which maximizes his/her expected utility (e.g. allows to derive the maximal level of utility from an activity with minimal costs of this activity).

As I mentioned in section 2.1., expected utility theory is a mathematical theory which is supposed to define the conditions under which the principle of maximization holds. It has been interpreted by decision theorists as a normative theory of decision making. Normative decision theory allows to formulate statements about what agents are rationally required to choose. Nevertheless, the founders of axiomatization for expected utility principle did not aspire to propose a normative theory of decision making. I have referred to J. von Neumann's and O. Morgenstern's work in detail in order to convince the readers that the authors did not understand their axiomatization in a normative manner. The normative dimension of expected utility theory has been ascribed to von Neumann and Morgenstern work by their followers and interpreters.

Expected utility theory (understood as axiomatization for maximization principle) is a formal theory, with neither normative nor descriptive claims. The proponents of the neoclassical approach in law \& economics interpret the theory in a normative way, arguing that people's decisions in legal contexts should be analyzed under assumption of (economic) rationality, but also in a descriptive way, claiming that analyses based on expected utility theory might be used in order to influence people's behavior. Therefore, I argue that the use of expected utility theory by EAL scholars is based on the misinterpretation of the theory assumptions and claims.

Formal expected utility theory allows to structure decisions taken in legal contexts in the way illustrated two paragraphs above. It also allows to construct the order of decisions, as well as to explicitly indicate formal conditions under which the structure and order hold. Any "applications" of expected utility theory which lead to the formulation of explanations and/or predictions of behavior/decisions in legal contexts are the misinterpretations of the theory, as well as excessive claims, unjustifiable on the basis of the theory.

\subsection{Behavioral law \& economics and prospect theory}

\subsubsection{Assumptions}

Prospect theory, as well as research on decision making under uncertainty (heuristics and biases research $)^{47}$ conducted also by A. Tversky and D. Kahneman, has inspired

${ }^{47}$ In this article I refer only to prospect theory, since I am interested in theories of decision making. Research on heuristics and biases has not yet led to the formulation of a theory. 
law \& economics scholars who have started to use the findings of behavioral sciences to analyze decisions made in legal contexts.

The term "behavioral law \& economics" appeared for the first time in a seminal article by Ch. Jolls, C. Sunstein and R. Thaler $A$ behavioral approach to law and econom$i c s^{48}$, which became a manifesto of behavioral approach in law \& economics. Nowadays, the methods of behavioral law \& economics are used in analyses of almost all branches of law. Its adherents are of the opinion that the behavioral approach constitutes improvement of and complement to the analyses employed in traditional (neoclassical) law \& economics. Nevertheless, the starting point of behavioral contribution to the economic analysis of law is criticism of the neoclassical approach.

Criticism is directed mainly at predictive power of neoclassical theories. It is based on both observation of behavior (mainly during experiments) in legal settings and challenging assumptions of the neoclassical approach. Behavioral scholars claim that in many legal contexts people do not behave in line with predictions of traditional law \& economics and that it is possible to generalize departures from those predictions. They test hypotheses about people's behavior formulated on the ground of neoclassical theories in economic analysis of law, and observe that in many experimental settings people systematically deviate from predictions of their behavior/choices derived from models of traditional (neoclassical) law \& economics.

The departures are systematic, predictable and called "bounds". Three systematic bounds of that kind are indicated, namely bounded willpower, bounded self-interest and bounded rationality.

Bounded willpower refers to the observation that people often choose actions knowing that these actions are in conflict with their long-term interest. Such behaviors come to play when people take decisions which have consequences over time. Due to hyperbolic discounting, they choose options which do not maximize their utility in the long run. ${ }^{49}$

Bounded self-interest concerns a phenomenon that in some contexts during processes of economic decision making people take into consideration not only their own interest but also the interest of others (even strangers). Decisions made in situations when people take into account also the others' interest are mainly explained as driven by trust - e.g. decisions in experiments examining people's behavior during strategic games (ultimatum game, trust game). Bounded self-interest occurs especially if one party of interaction behaves in a way which departs from the usual conduct under the circumstances and the behavior of the second party is aimed at "punishing" such departures as unfair. ${ }^{50}$

Bounded rationality relates to formulation of judgments and decision making. It is based on the observation that people have limited computational skills and flawed

48 Ch. Jolls, C. Sunstein, R. Thaler, A behavioral approach to law and economics, "Stanford Law Review" 1998/50/5, pp. $1471-1550$.

49 Hyperbolic discounting is a term used for someone's declining rate of time preference. It takes place e.g. in choice situations in which "subjects are asked to compare a smaller - sooner reward to a larger - later reward, the implicit discount rate over longer time horizons is lower than the implicit discount rate over shorter time horizons" (S. Frederick, G. Loewenstein, T. O’Donoghue. Time discounting and time preference. A critical review, "Journal of Economic Literature" $2002 / 40 / 2$, p. 360). For example, if an agent is asked to choose between $15 \$$ available in 10 days and $10 \$$ available in 9 days, he/she chooses the first option ( 15 \$ preferred to $10 \$)$. However, an agent choosing between $10 \$$ available now (today) and $15 \$$ available next day (tomorrow), prefers $10 \$$ now. Amounts of money are the same in case of both choices. The decisions differ if the amounts are seen from different time perspectives.

50 The ultimatum game is a game in which the first player is given a sum of money and told to determine how much to give to the second player. The second player can then either accept or reject it. In the latter case, neither player gets payoff. 
memories. In some situations they do not behave in accordance with predictions of the neoclassical models, but use e.g. heuristics that might lead them to cognitive errors or violate predictions of expected utility theory. Behavioral scholars divide departures from rational choice theory into two categories: those concerning judgment and those concerning decision making. "Actual judgments show systematic departures from model of unbiased forecasts, and actual decisions often violate the axioms of expected utility theory." ${ }^{51}$ Reliance on heuristics might lead to biases, whereas some decisions under risk substantially differ from predictions of expected utility theory and are explained on the ground of prospect theory.

Behavioral scholars differentiate between three tasks of the behavioral approach to law: positive, prescriptive and normative. The positive analysis constitutes the greatest field of behavioral law \& economics and law \& economics itself. It concerns both impact of law on human behavior (expressed in the question: "How will law affect human behavior?"52) and explanation of the content of law ("Why does law take the form that it does? ${ }^{53 ")}$. The prescriptive aim of the behavioral approach is directed at making use of law in order to steer people's behavior and achieve specified ends. Finally, the normative task relies on assessment of ends of the whole legal system and it is achieved mainly by the contribution of behavioral scholars to the discussion about paternalism in law.

\subsubsection{Example of analysis based on prospect theory - litigation and settlement ${ }^{54}$}

Prospect theory has been applied i.a. in order to explain decisions taken by plaintiffs and defendants in courts. The proponents of behavioral law \& economics criticize neoclassical analyses, which lead to the conclusion that virtually every (civil) court case is supposed to be settled. According to neoclassical scholars, potential plaintiffs or defendants, while deciding whether to settle or litigate a case, face a problem of maximization. Before they choose an alternative which maximizes the outcomes, they compare utility of settlement with the expected utility of litigation. Choosing settlement results in getting sure payoff. Since their utility function is concave, they are risk averse and prefer sure gain over the merely probable (risky) one. Expected utility of a trial is diminished by the transaction costs related to litigation. EAL scholars claim that transaction costs almost always exceed the costs of settlement and for that reason almost every case should be settled.

The adherents of behavioral law \& economics are of the opinion that agents who reconsider decisions whether to settle or to sue, do not assign values to the expected outcomes of their choice. They rather perceive relevant options as gains or losses, and value these options from the current position (reference point). If they perceive a choice problem as a choice between losses, they have a tendency to exhibit risk seeking. However, if the alternatives are perceived as gains, they tend to induce risk aversion. According to prospect theory, agents (in that case - defendants or plaintiffs) underweight the probabilities attached to trial outcomes.

Different decision frames are attributed to decisions of plaintiffs and defendants. Plaintiffs who start a dispute, while choosing between settling or starting a trail, face

51 Ch. Jolls, C. Sunstein, R. Thaler, A behavioral approach..., p. 1477.

52 Ch. Jolls, C. Sunstein, R. Thaler, A behavioral approach..., p. 1474.

53 Ch. Jolls, C. Sunstein, R. Thaler, A behavioral approach..., p. 1474.

54 D.C. Langevoort, Behavioral Theories of Judgment and Decision Making in Legal Scholarship: A Review of Literature, "Vanderbilt Law Review"1998/51, pp. 1499-1526. 
a choice between: getting a certain settlement (riskless component, perceived as a gain) or receiving a higher amount of money at a trial with a given probability (risky component). They make a choice in a positive domain of gains and for that reason they are risk averse. It means that they prefer settlement to the risky option of trail.

On the other hand, defendants perceive this problem as a choice between: paying a certain amount of money during a settlement (riskless component, perceived as a loss) or losing a higher amount with a given probability at a trail (risky component). They make a choice in a negative domain of losses. Therefore, they have a tendency to choose trail - the risk seeking option.

As in the case of economic analysis of tort law, the abovementioned example might be conceptualized as a decision theoretic problem. Acts which are considered by an agent, are as the following: "to settle" or "to go to trail". States depend on the magnitude of transaction costs in case of the neoclassical analysis or on being in a situation of defendant or plaintiff in case of the behavioral approach. Outcomes are determined by the expected costs of trail in the neoclassical case or by the subjective and weighted function of changes in wealth in the behavioral analysis.

In contrast with the analyses based on expected utility theory, the analyses based on prospect theory do not "abuse" the theory of A. Tversky and D. Kahneman. Prospect theory is a descriptive theory of decision making under risk which generalizes observations of choice in experimental situations. The analysis of decisions about settlement or trail conceptualizes choices in litigation context in accordance with theoretical frames of prospect theory and describes behavior in line with of the theory claims.

Prospect theory is a model of decision making, but it does not explain a mechanism responsible for choices. ${ }^{55}$ In other words, it states e.g. that in negative domains people have tendencies to exhibit risk seeking behaviors, but it does not provide an explanation why they are eager to risk in order to avoid loss. Therefore, my point is that also in case of the analyses based on prospect theory, the EAL scholars formulate excessive claims concerning a possibility to use behavioral findings in order to explain how law influences behavior. First of all, prospect theory informs us only about propensities to act/decide in a particular way. As long as the mechanism of processes of decision making remains unexplained, it is not possible to predict anything more than tendencies in behavior, also in legal contexts. Secondly, the analysis of litigation behavior does not concern the impact of legal norms on behavior. It focuses rather on the behavior within frames defined/structured by law. Therefore, on the basis of analysis of that kind, we are not allowed to draw conclusions about how people will respond to legal rules. What we can state, is a description of what their propensities to act will be in situations framed by legal rules.

\section{Conclusions}

Law \& economics may be treated as a proposal of a theory of decision making in legal contexts. Application of two theories of decision making (expected utility theory and prospect theory) to law is justified from instrumental, behavioral and political perspective. From this point of view law is treated as an institutional tool which is used to influence behavior of its addressees.

55 The same argument might be formulated in case of expected utility theory. I refer to this point again in conclusions. 
I decided to reconstruct the assumptions, propositions and claims of two influential theories of decision making in order to examine whether and to what extent the analyses of the EAL scholars have decision theoretical foundations. I came to conclusion that these scholars misinterpret the assumptions of both theories and/or formulate excessive claims with respect to the possibility to use findings of these theories in legal contexts.

Expected utility theory is interpreted as a normative and/or descriptive theory of decision making, whereas it has a formal character. If the proponents of the neoclassical approach treat the theory as an empirical one, they formulate unjustifiable claims about the possibility of using analyses based on expected utility theory in order to explain and predict directions of impact of legal norms on behavior.

Prospect theory is interpreted in accordance with its descriptive character, but behavioral scholars seem not to realize that it allows only for analyses of propensities for particular behavior.

If one takes a closer look at the structure and propositions of the theories of decision making applied in EAL, it is plausible to say that both theories do not, in fact, explain the mechanism of decision processes. They are rather formalizations - of maximization principle present in economics (in the case of expected utility theory), of observations of choices in experimental situations (in the case of prospect theory). Therefore, they do not provide explanations why decisions are taken in a particular way and which factors have an influence on choosing a particular alternative.

If we do not know mechanisms behind the processes of decision making, even less we are able to state (theoretically) about law as a factor influencing behavior. Therefore, it might seem rather puzzling what forms the basis for the convictions (expressed in the citations from EAL works which I started my article with) that the theories of decision making applied in legal contexts inform us about the influence of law on behavior. Theories of decision making provide us with the knowledge about e.g. constraints under which it is possible to define maximization or about tendencies to decide in particular way. This knowledge might be obviously useful for law makers and/or judges (e.g. it might make them attentive to formulations of legal norms or rulings in terms of gains or losses). However, the claim that law might alter behavior in a desirable direction presupposes that there is a well defined link between law and behavior. Is relation between legal norms and behavior the causal one? Does it have rather a probabilistic character? Are we allowed to draw conclusions about impacts of law on behavior without reflecting the nature of the relation between law and behavior? The analyses of behaviors in legal contexts based on the theories of decision making provoke questions of that kind and leave them open. 


\section{BIBLIOGRAFIA / REFERENCES:}

Alchian, A. (1965). Some Economics of Property Rights. Il Politico 30/4, 816-829.

Allais, M. (1953). Le Comportement de l'Homme Rationnel devant le Risque: Critique des Postulats et Axiomes de 1'Ecole Americaine. Econometrica 21/4, 503-546.

Arlen, J.H., Talley, E.L. (2008). Experimental Law and Economics. Cheltenham: Edward Elgar Publishing.

Blaug, M. (1992). Methodology of Economics or How Economists Explain. Cambridge: Cambridge University Press.

Calabresi, G. (1961). Some Thoughts on Risk Distributions and the Law of Torts. Yale Law Journal 70/4, 499-553.

Coase, R. (1960). The Problem of Social Cost. Journal of Law and Economics 3, 1-44.

Cooter, R., Ulen, T. (2004). Law \& Economics. Boston: Pearson-Addison Wesley.

Frederick, S., Loewenstein, G., O’Donoghue, T. (2002). Time Discounting and Time Preference: A Critical Review. Journal of Economic Literature 40/2, 351-401.

Jolls, C., Sunstein, C., Thaler, R. (1998). A Behavioral Approach to Law and Economics. Stanford Law Review 50/5, 1471-1550.

Kahneman, D., Tversky, A. (1979). Prospect Theory: An Analysis of Decision under Risk. Econometrica 47/2, 263-292.

Langevoort, D.C. (1998). Behavioral Theories of Judgment and Decision Making in Legal Scholarship: A Review of Literature. Vanderbilt Law Review 51/6, 1499-1540.

von Neumann, J., Morgenstern, O. (1947). Theory of Games and Economic Behavior. Princeton: Princeton University Press.

Peterson, M. (2009). An Introduction to Decision Theory. Cambridge: Cambridge University Press.

Posner, R.A. (1972). Economic Analysis of Law. Boston: Little, Brown and Company.

Posner, R.A. (1987). The decline of law as an autonomous discipline: 1962-1987. Harvard Law Review $761,761-780$.

Samuelson, P. (1937). A Note on Measurement of Utility. The Review of Economic Studies 4/2, 155161.

Shavell, S. (2007). Liability for accidents. In M. Polinsky, S. Shavell (Eds.), Handbook of Law and Economics (pp. 139-182). Amsterdam: Elsevier.

Sunstein, C. (2000). Introduction. In C. Sunstein (Ed.), Behavioral Law \& Economics. Cambridge: Cambridge University Press. 